И.Н.Трофименко, Б.А.Черняк

Бронхиальная гиперреактивность как фенотипическая
характеристика хронической обструктивной болезни легких

ГОУ ДПО "Иркутский государственный институт усовершенствования врачей": 664079, Иркутск, м / р Юбилейный, 100

\title{
I.N.Trofimenko, B.A.Chernyak \\ Bronchial hyperresponsiveness as a phenotypic feature of chronic obstructive pulmonary disease
}

\begin{abstract}
Summary
The aim of the study was to compare clinical and functional features and health-related quality of life in chronic obstructive pulmonary disease (COPD) patients with regard to bronchial hyperresponsiveness as a phenotypic sign. Clinical and functional status, quality of life and results of metacholine challenge test were analysed in 75 moderate-to-severe COPD patients. According to the results of methacholine challenge test the patients were divided into two groups: patients having positive metacholine challenge test results (group 1; $\mathrm{PD}_{20}<0.471 \mathrm{mg}$ ) and patients having negative metacholine challenge test results (group 2; $\mathrm{PD}_{20}>0.471 \mathrm{mg}$ ). Bronchial hyperresponsiveness was revealed in 52 of $75(69 \%)$ patients. Severity of respiratory symptoms was higher in the group 1 patients. Bronchial hyperresponsiveness contributed to severity of dyspnea in COPD $(\mathrm{OR}=8.6$; $p=0.007$ ). The quality of life of the group 1 patients was worse than that of the group 2 patients. However, no significant difference was found between the groups for $\mathrm{FEV}_{1}$. Thus, COPD with bronchial hyperresponsiveness is characterized by more severe course of the disease and could be considered as a separate phenotype of COPD

Key words: bronchial hyperresponsiveness, chronic obstructive pulmonary disease, severity, quality of life, clinical features, phenotype.
\end{abstract}

\section{Резюме}

Целью исследования явилось сравнительное изучение клинико-функциональных особенностей и качества жизни (КЖ) у больных хронической обструктивной болезнью легких (ХОБЛ) в зависимости от уровня бронхиальной реактивности как возможного фенотипического признака. У 75 амбулаторных пациентов с ХОБЛ средней степени тяжести проанализированы показатели клиникофункционального статуса и КЖ. Пациенты стратифицированы на 2 группы: у пациентов 1-й группы $(n=52)$ тест с метахолином был положительным (провокационная доза (ПД 2 ), вызвавшая снижение величины объема форсированного выдоха за 1-ю с $\left(\mathrm{OФB}_{1}\right)$ на $\geq 20 \%$ от исходного значения, $-\geq 0,471$ мг), у больных 2 -й группы $(n=23)-$ отрицательным (ПД $20->0,471)$. Респираторные симптомы больных 1-й группы характеризовались большей степенью выраженности. Выявлена взаимосвязь степени одышки с уровнем бронхиальной реактивности (отношение шансов $-8,6 ; p=0,007$ ). Показатели КЖ в 1-й группе были достоверно ниже, чем во 2-й. При этом значения ОФВ 1 были сопоставимы в обеих группах. Таким образом, клинический вариант ХОБЛ с бронхиальной гиперреактивностью может рассматриваться в качестве отдельного фенотипа заболевания, характеризующегося более тяжелым течением.

Ключевые слова: бронхиальная гиперреактивность, хроническая обструктивная болезнь легких, тяжелое течение, качество жизни, клинический вариант, фенотип.

В настоящее время в целях клинико-функциональной характеристики больных хронической обструктивной болезнью легких (ХОБЛ), определения степени ее тяжести и выбора объема терапии преимущественно используется оценка выраженности бронхиальной обструкции. Основанием для последней является спирометрический показатель объем форсированного выдоха за 1-ю с $\left(\mathrm{OФB}_{1}\right)$. На протяжении длительного времени этот параметр служил индикатором темпа прогрессирования ХОБЛ и степени риска летального исхода [1]. Вместе с тем, как показывают накопленные за последние годы многочисленные данные, классификация ХОБЛ, основанная только на спирометрических показателях, не отражает всего многообразия патогенетических, клинико-функциональных и терапевтических особенностей патологии. Даже в пределах одной стадии заболевания (в достаточно узком диапазоне ОФВ 1 ) у пациентов с ХОБЛ (в т. ч. при тяжелом течении) наблюдается широкая вариабельность клинических проявлений: одышки, толерантности к физической нагрузке, частоты обострений и сопутствующей патологии, качества жизни (КЖ) [2, 3]. Следует отметить и то обстоятельство, что помимо ОФВ 1 предикторами прогрессирования и летальности при ХОБЛ выступают и другие клинико-функциональные признаки заболевания. Так, 5-летняя выживаемость больных ХОБЛ достоверно связана с уровнем одышки $(p<0,001)$, но не с показателями $\mathrm{OФB}_{1}(p=0,20)[4]$, а толерантность к физической нагрузке является более значимым предиктором смертности, чем ОФВ 1 , вне зависимости от степени бронхиальной обструкции и возраста больных $[5,6]$. Высокий прогностический уровень риска смертности при ХОБЛ показан также для параметров легочной гиперинфляции [7], бронхиальной гиперреактивности (БГР) [8], низкого индекса массы тела (ИМТ) [9]. Таким образом, ОФВ, , будучи общепринятым маркером тяжести бронхиальной обструкции, не отражает гетерогенности клинических 
особенностей ХОБЛ, в т. ч. ее экстрапульмональный компонент, и, в частности, сердечно-сосудистую патологию, которая не только утяжеляет течение самой болезни, но и нередко является главной причиной госпитализаций и летальных исходов у больных [10-13].

Изложенные выше положения легли в основу новой концепции, согласно которой ХОБЛ рассматривается как заболевание не только патогенетически многокомпонентное, но и характеризующееся фенотипической гетерогенностью [13-15]. Под фенотипом обычно понимается набор признаков, развившихся в результате взаимодействия генотипа и внешней среды. Применительно к ХОБЛ фенотип определяется экспертами как характерная черта или комбинация таких черт, которые описывают различия между пациентами, связанные с клинически значимыми проявлениями (симптомами, обострениями, ответом на терапию, скоростью прогрессирования заболевания или смертью) [14]. В настоящее время кроме уже достаточно давно описанных вариантов ХОБЛ - эмфизематозного и бронхитического - выделяют следующие фенотипы: буллезная болезнь; с ранним началом; с частыми обострениями; ХОБЛ у женщин; ХОБЛ в сочетании с бронхиальной астмой и др. [16]. Суть выделения фенотипов ХОБЛ состоит в идентификации отдельных групп больных, сопоставимых по клинико-функциональным признакам и профилю терапевтического ответа вследствие аналогичных биологических или патофизиологических механизмов заболевания.

Целью настоящего исследования явилось сравнительное изучение клинико-функциональных особенностей и КЖ у больных ХОБЛ в зависимости от уровня бронхиальной реактивности как возможного фенотипического признака.

\section{Материалы и методы}

В исследование были включены 75 амбулаторных больных ХОБЛ средней степени тяжести в возрасте от 42 до 80 лет (средний возраст $-57 \pm 7$ лет), среди них - 66 мужчин и 9 женщин. Диагностика ХОБЛ, включая оценку степени тяжести, осуществлялась на основании критериев Глобальной инициативы по лечению и профилактике ХОБЛ (GOLD) [1]. Bсе пациенты, в том числе и бывшие курильщики, имели индекс курения > 10 пачек / лет.

Были проанализированы показатели клиникофункционального статуса и КЖ больных ХОБЛ. Интенсивность респираторных симптомов оценивалась с использованием стандартизованных шкал: дневного и ночного кашля - по 5-балльной аналоговой шкале [17], одышки - по 4-балльной шкале MRC. Оценка показателей легочной функции проводилась на основании результатов спирометрии (Schiller Spirovit 1, Швейцария) исходно и после ингаляции 400 мкг Вентолина. Для исследования толерантности к физической нагрузке в соответствии со стандартным протоколом проводился 6-минутный шаговый тест (6-МШТ), который включал в себя оценку пройденного расстояния (в метрах) и выраженность одышки в конце теста по 10-балльной аналогововизуальной шкале Борга (0 - отсутствие одышки, 10 - максимальная одышка). КЖ оценивалось с помощью специализированного Вопросника Госпиталя св. Георгия (SGRQ). Анализ показателей КЖ проводился по каждому домену вопросника "Симптомы", "Активность", "Влияние", определялось общее КЖ (сумма баллов).

Выраженность системного воспаления анализировали на основании концентрации биомаркеров в сыворотке крови - интерлейкинов 6 и 8 (IL-6, IL-8) и фактора некроза опухоли- $\alpha$ (TNF- $\alpha$ ), которые определялись посредством твердофазного иммуноферментного анализа (использовались реагенты "Вектор-Бест", Россия). Кроме того, применялся слайд-тест для качественного и полуколичественного определения С-реактивного белка (СРБ) (наборы реагентов Human, Германия).

У всех пациентов проведено исследование реактивности бронхов в ингаляционном провокационном тесте с метахолином (ИПТм) посредством резервуарного метода (Pari Provotest 2, Германия) [18]. В соответствии с протоколом первоначально ингалировался изотонический раствор $\mathrm{NaCl}$ с последующим проведением непосредственно ИПТм. Тест прекращался при падении показателя ОФВ $1 \geq 20 \%$ от исходного значения. В случае отсутствия снижения $\mathrm{OФB}_{1} \geq 20 \%$ при провокационной дозе (ПД 20 ), достигшей 0,471 мг, тест расценивался как отрицательный. Степень БГР оценивалась на основании показателя кумулятивной дозы метахолина, вызывавшей снижение величины ОФВ 1 на $\geq 20 \%$ от исходного значения. ПД 20 рассчитывали методом линейной интерполяции по общепринятой формуле [18]:

$$
\text { ПД } 20=\operatorname{antilog}\left\{\log C_{1}+\left(\log C_{2}-\log C_{1}\right) \times\left(20-R_{1}\right) /\left(R_{2}-R_{1}\right)\right\},
$$

где $\mathrm{C}_{1}$ - предпоследняя доза метахолина (изменение ОФВ $\left.\mathrm{B}_{1}<20 \%\right), \mathrm{C}_{2}-$ последняя доза метахолина (изменение ОФВ $120 \%$ ), $\mathrm{R}_{1}$ - снижение ОФВ 1 после $\mathrm{C}_{1}, \mathrm{R}_{2}-\%$ снижения ОФВ 1 после $\mathrm{C}_{2}$.

Статистическая обработка результатов проводилась при помощи методов вариационной статистики. Для сравнительного анализа результатов исследования использовался критерий Манна-Уитни.

\section{Результаты и обсуждение}

Положительный метахолиновый тест, свидетельствующий о наличии БГР, зарегистрирован у 52 из 75 $(69,3 \%)$ больных ХОБЛ. По результатам ИПТм пациенты были разделены на 2 группы: в 1-ю группу (БГР+) включены 52 человека с положительным тестом (ПД $20 \leq 0,471$ мг), во 2-ю (БГР-) - 23 пациента с отрицательным тестом (ПД $20>0,471)$ (табл. 1).

Обе группы достоверно не различались по возрасту, однако частота и степень БГР существенно изменялись в зависимости от пола больных. Так, у женщин с ХОБЛ ИПТм был положительным в 88,9 \% случаев (у 8 из 9 пациенток), тогда как среди мужчин 
Таблица 1 Клиническая характеристика больных

\begin{tabular}{|c|c|c|c|}
\hline Показатели & 1-я группа $(n=52)$ & 2-я группа $(n=23)$ & $p$ \\
\hline Возраст, годы & $56,4 \pm 6,0$ & $59,4 \pm 8,6$ & 0,19 \\
\hline $\begin{array}{l}\text { Индекс курения, } \\
\text { пачек / лет }\end{array}$ & $40,5 \pm 18,3$ & $37,2 \pm 17,0$ & 0,44 \\
\hline $\begin{array}{l}\text { Длительность ХОБЛ, } \\
\text { годы }\end{array}$ & $9,6 \pm 5,9$ & $4,4 \pm 2,1$ & 0,002 \\
\hline ИМТ, кг / м $^{2}$ & $29,0 \pm 7,6$ & $24,8 \pm 4,2$ & 0,003 \\
\hline
\end{tabular}

БГР встречалась в 66,7 \% случаев (у 44 из 66 больных). Помимо большей частоты БГР у женщин выявлена и ее более высокая степень: среднее значение ПД 20 у них составило 0,024 мг, по сравнению с 0,121 мг у мужчин $(p=0,01)$. Данные других исследователей также подтверждают более высокую частоту БГР у женщин с ХОБЛ [19, 20]. Предполагается, что существующие гендерные различия БГР у больных ХОБЛ связаны либо с особенностями гормонального статуса женщин, либо с морфологическими различиями - у женщин диаметр воздухоносных путей меньше даже при сопоставимых с мужчинами параметрах бронхиальной обструкции [21].

Оценка влияния табакокурения на БГР не выявила достоверных различий в сравниваемых группах (табл. 1), однако у пациентов 1-й группы с индексом курения > 35 пачек / лет значения ПД 20 были более низкими, что соответствует более высокому уровню БГР.

Анализ индекса массы тела в зависимости от уровня БГР выявил существенные межгрупповые различия: среднее значение ИМТ больных с положительным ИПТм было достоверно выше по сравнению с пациентами без БГР (табл. 1). В этом аспекте заслуживают внимания имеющиеся данные о взаимосвязи между уровнем системных биомаркеров воспаления и массой тела. В частности, показано увеличение содержания в сыворотке крови IL-6, СРБ, TNF- $\alpha$ у пациентов с избыточной массой тела и ожирением [22, 23]. Приведенные данные корреспондируют с результатами нашего исследования, в котором определяется достоверно более высокий уровень IL-6 и IL-8 в сыворотке крови больных с БГР (табл. 2). Оценка уровней IL-6 и IL-8 в сравниваемых группах позволяет предположить определенное влияние на формирование БГР у больных ХОБЛ не только механизмов локального, но и системного воспаления.

Сравнительный анализ выраженности респираторных симптомов в зависимости от результатов

Таблица 2

Концентрация системных биомаркеров в сыворотке крови больных ХОБЛ в зависимости от БГР

\begin{tabular}{|l|r|r|c}
\multirow{2}{*}{ Биомаркеры } & \multicolumn{2}{|c|}{ Mean \pm SD } & \multirow{2}{*}{$p$} \\
\cline { 1 - 3 } & БГР+ & БГР- & \\
\hline TNF- $\alpha$, пг / мл & $4,29 \pm 2,72$ & $3,40 \pm 1,84$ & 0,298 \\
IL-6, пг / мл & $5,35 \pm 5,11$ & $2,55 \pm 2,83$ & 0,032 \\
\hline IL-8, пг / мл & $10,19 \pm 4,15$ & $7,52 \pm 2,24$ & 0,008 \\
\hline СРБ, мг / л & $5,42 \pm 8,25$ & $4,13 \pm 7,50$ & 0,500 \\
\hline
\end{tabular}

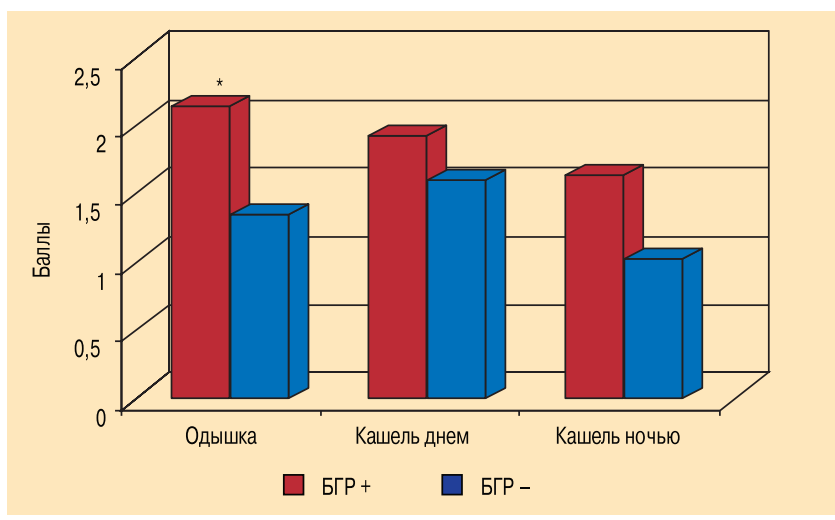

Рис. 1. Выраженность респираторных симптомов в зависимости от результатов метахолинового теста Примечание: ${ }^{*}-p=0,0003$

ИПТм выявил существенные различия между группами (рис. 1). Одышка большей степени интенсивности зарегистрирована в 1-й группе. Разница показателей по шкале MRC составила в среднем 0,8 балла $(p=0,0003)$. Аналогичная тенденция складывалась и при оценке интенсивности кашля - как в дневное время, так и ночью. Кроме того, у больных с тяжелой одышкой (III степени по шкале MRC) БГР характеризовалась достоверно более высоким уровнем по сравнению с пациентами, которые оценивали одышку как легкую и умеренную (I и II степени по шкале MRC). Среднее значение ПД 20 у больных с тяжелой одышкой было в 2,2 раза ниже по сравнению с пациентами, у которых выраженность этого симптома достигала I-II степени $(p=0,029)$. Полученные данные свидетельствуют о взаимосвязи степени одышки с уровнем БГР у больных ХОБЛ и подтверждаются результатами корреляционного и логистического регрессионного анализа. Корреляционная связь между степенью одышки и ПД 20 при использовании метода Спирмена характеризовалась умеренной обратной зависимостью $(r=-0,51$; $p<0,001)$. При оценке БГР как фактора риска тяжелой одышки показатель "отношение шансов" (ОШ) составил 8,6 (CI 1,6 < OR < 51,5; $p=0,007)$. При этом следует отметить, что показатели ОФВ 1 до и после применения бронходилататора были сопоставимы в обеих группах больных ХОБЛ (табл. 3). Таким образом, БГР можно рассматривать как предиктор тяжелой одышки у больных ХОБЛ и соответственно более тяжелого течения заболевания. Между группами обнаружена значительная разница значений форсированной жизненной емкости легких (ФЖЕЛ) до приема бронхолитика, которая нивелируется после использования препарата.

При сравнении толерантности к физической нагрузке также выявлены различия между группами (табл. 3). Если пройденное расстояние в 6-МШТ в обеих группах существенно не различалось, то одышка физического усилия, оцененная по шкале Борга, у больных с БГР была в среднем на 1,1 балла выше $(p<0,05)$.

Уровень реактивности бронхов влиял и на показатели КЖ у больных. Так, в 1-й группе КЖ было достоверно ниже по всем доменам в сравнении 
Таблица 3

Показатели спирометрии и 6-МШТ в зависимости от БГР

\begin{tabular}{|c|c|c|c|}
\hline \multirow[t]{2}{*}{ Параметры } & \multicolumn{2}{|c|}{ Mean $\pm S D$} & \multirow[t]{2}{*}{$p$} \\
\hline & БГР+ & БГР- & \\
\hline $\begin{array}{l}\text { ОФВ }{ }_{1} \text { до бронходи- } \\
\text { лататора, \% \%опж. }\end{array}$ & $58,1 \pm 8,4$ & $60,5 \pm 9,1$ & 0,217 \\
\hline $\begin{array}{l}\text { ОФВ } 1 \text { после бронхо- } \\
\text { дилататора, \% \%олк. }\end{array}$ & $65,6 \pm 8,5$ & $65,8 \pm 7,2$ & 0,698 \\
\hline $\begin{array}{l}\text { ФЖЕЛ до бронходи- } \\
\text { лататора, \% } \text { долж. }^{\text {. }}\end{array}$ & $73,2 \pm 18,0$ & $80,0 \pm 20,8$ & 0,042 \\
\hline $\begin{array}{l}\text { ФЖЕЛ после бронхо- } \\
\text { дилататора, \% оолж. }\end{array}$ & $86,7 \pm 10,7$ & $91,6 \pm 13,5$ & 0,338 \\
\hline 6-МШТ, м & $470,4 \pm 62,6$ & $475,7 \pm 70,4$ & 0,772 \\
\hline Одышка Борга, баллы & $3,7 \pm 1,2$ & $2,6 \pm 0,8$ & 0,002 \\
\hline
\end{tabular}

с пациентами 2-й группы, у которых БГР отсутствовала (рис. 2). При этом значения межгрупповых различий достигали очень высокого уровня. В частности, разница средних значений показателей для домена "Симптомы" составила 23,6 балла ( $p=0,000001)$, для домена "Активность" - 14,4 балла $(p=0,0046)$, домена "Влияние" - 12,9 балла $(p=0,008)$ и домена "Общее КЖ" - 15,3 балла $(p=0,001)$.

Таким образом, проведенное нами исследование клинико-функционального статуса и КЖ у больных показало, что феномен БГР является фактором, существенно модифицирующим течение ХОБЛ и повышающим степень ее тяжести. Вместе с тем, анализируя возможное влияние БГР на течение заболевания, следует отметить еще одно важное обстоятельство. В ряде долгосрочных исследований показано, что БГР является независимым предиктором развития ХОБЛ. Так у пациентов с "асимптомной" БГР, независимо от статуса курения, в течение 3-летнего периода риск развития симптомов ХОБЛ оказался значительно выше, чем у лиц без БГР: для хронического кашля, хронической продукции мокроты и тяжелой одышки показатель ОШ соответственно составил 1,9; 2,0 и 2,3 [24]. Более продолжительное 11-летнее - проспективное исследование SAPALDIA Cohort Study [20] убедительно подтвердило эти результаты. Было показано, что БГР повышает риск развития ХОБЛ более чем в 4 раза: ОШ $=4,5$ $(3,3-6,0 ; p<0,001)$.

Как было отмечено выше, фенотипы не только определяют клинические особенности заболевания, но и могут явиться предикторами характера ответа

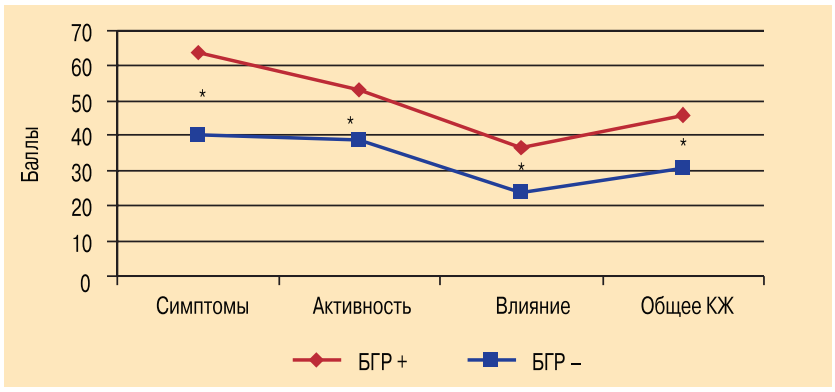

Рис. 2. Показатели КЖ в зависимости от результатов метахолинового теста

Примечание: ${ }^{*}-p<0,01$. на назначаемую терапию. В этом контексте представляют интерес результаты единственного исследования, касающегося БГР при ХОБЛ. Авторы этой работы показали, что БГР может рассматриваться как предиктор эффективности терапии ингаляционными глюкокортикостероидами у больных среднетяжелой ХОБЛ. Так, у таких пациентов в тесте с маннитолом через 3 мес. лечения иГКС произошел прирост добронходилатационного ОФВ 1 в среднем на $12 \%$, тогда как у пациентов с отрицательным результатом теста подобная динамика отсутствовала [25].

\section{Заключение}

У значительной части пациентов со среднетяжелой ХОБЛ имеет место БГР, которая ассоциируется не только с более выраженными респираторными симптомами, но и снижением толерантности к физическим нагрузкам и показателей КЖ. Полученные результаты, а также данные литературы позволяют рассматривать БГР у пациентов с ХОБЛ как фактор, модифицирующий развитие патологии и отражающий гетерогенность ее клинико-функциональных проявлений. Изучение БГР при ХОБЛ позволяет получить дополнительную информацию об особенностях клинического течения, его тяжести, прогнозе и возможном ответе на противовоспалительную терапию. Таким образом, клинический вариант ХОБЛ, сочетающийся с БГР, может рассматриваться в качестве отдельного фенотипа заболевания. Основанием для подобного заключения является следующее: БГР определяется не у всех пациентов с ХОБЛ, является независимым предиктором заболевания, утяжеляет его течение, снижает КЖ и увеличивает риск смертности.

\section{Литература}

1. Global Initiative for Chronic Obstructive Lung Disease (GOLD). Global Strategy for the Diagnosis, Management, and Prevention of Chronic Obstructive Pulmonary Disease. 2009. www.goldcopd.com

2. Agusti A., Calverley P.M.A., Celli B. et al. Characterisation of COPD heterogeneity in the ECLIPSE cohort. Respir Res 2010; 11 (1): 122. http://respiratory-research.com/content/ $11 / 1 / 122$

3. Трофименко И.Н., Черняк Б.А. Взаимосвязь клиникофункционального статуса и качества жизни у больных хронической обструктивной болезнью легких. Сиб. консилиум 2008; 1 (64): 48-52.

4. Nishimura K., Izumi T., Tsukino M. et al. Dyspnea is a better predictor of 5-year survival than airway obstruction in patients with COPD. Chest 2002; 121: 1434-1440.

5. Gerardi D.A., Lovett L., Benoit-Connors M.L. et al. Variables related to increased mortality following out-patient pulmonary rehabilitation. Eur. Respir. J. 1996; 9: 431-435.

6. Oga T., Nishimura K., Tsukino M. et al. Analysis of the Factors related to mortality in chronic obstructive pulmonary disease. Am. J. Respir. Crit. Care Med. 2003; 167: 544-549.

7. Casanova C., Cote C., de Torres J.P. et al. The inspiratory to total lung capacity ratio predicts mortality in patients with COPD. Am. J. Respir. Crit. Care Med. 2005; 171: 591-597. 
8. Hospers J.J., Postma D.S., Rijcken B. et al. Histamine airway hyper-responsiveness and mortality from chronic obstructive pulmonary disease: a cohort study. Lancet 2000; 356: 1313-1317.

9. Schols A.M., Slangen J., Volovics L., Wouters E.F. Weight loss is a reversible factor in the prognosis of chronic obstructive pulmonary disease. Am. J. Respir. Crit. Care Med. 1998; 157: 1791-1797.

10. Agust A., Noguera A., Sauleda J. et al. Systemic effects of chronic obstructive pulmonary disease. Eur. Respir. J. 2003; 21: $347-360$.

11. Wouters E.F. COPD: from an organ- to a disease-oriented approach. COPD 2008; 5 (2): 73-74.

12. Agusti A. COPD, a multicomponent disease: implications for management. Respir. Med. 2005; 99: 670-682.

13. Burgel P. R., Paillasseur J.L., Caillaud D. et al. Clinical COPD phenotypes: a novel approach using principal component and cluster analyses. Eur. Respir. J. 2010; 36: 531-539.

14. Han M.K., Agusti A., Calverley P.M. et al. COPD phenotypes: The future of COPD. Am. J. Respir. Crit. Care Med. 2010; 182: 598-604.

15. Авдеев С.Н. Фенотипы хронической обструктивной болезни легких: особенности терапии. Consilium medicum 2010; прилож.: 23-28.

16. Garsia-Aymerich J., Agusti A., Barbera J.A. et al. Phenotypic heterogenetiy of chronic obstructive pulmonary disease. Arch. Broncopneumol. 2009; 45: 133-142.

17. Gulsvik A., Refvem O.K. Ascoring system on respiratory symptoms. Eur. Respir. J. 1988; 1: 428-432.

18. Чучалин А.Г. (ред.). Стандартизация легочных функциональных тестов. Пер. с англ. М.; 1993.

19. Kanner R.E., Connett J.E., Altose M.D. et al. Gender difference in airway hyperresponsiveness in smokers with mild
COPD. The Lung Health Study. Am. J. Respir. Crit. Care Med. 1994; 150 (4): 956-961.

20. Brutsche M.H., Downs S.H., Schindler C. et al. Bronchial hyperresponsiveness and the development of asthma and COPD in asymptomatic individuals: SAPALDIA Cohort Study. Thorax 2006; 61: 671-677.

21. Grootendorst D.C., Rabe K.F. Mechanisms of bronchial hyperreactivity in asthma and chronic obstructive pulmonary disease. Proc. Am. Thorac. Soc. 2004; 1: 77-87.

22. Khaodhiar L., Ling P.R., Blackburn G.L. et al. Serum levels of interleukin- 6 and C-reactive protein correlate with body mass index across the broad range of obesity. J. Parenter. Enter. Nutr. 2004; 28 (6): 410-415.

23. Bahceci M., Gokalp D., Bahceci S. et al. The correlation between adiposity and adiponectin, tumor necrosis factor alpha, interleukin- 6 and high sensitivity $\mathrm{C}$-reactive protein levels. Is adipocyte size associated with inflammation in adults? J. Endocrinol. Invest. 2007; 30 (3): 210-214.

24. Xu X., Rijcken B., Schouten J.P. et al. Airways responsiveness and development and remission of chronic respiratory symptoms in adults. Lancet 1997; 350: 1431-1434.

25. Leuppi J.D., Tandjung R., Anderson S.D. et al. Prediction of treatment-response to inhaled corticosteroids by mannitolchallenge test in COPD. A proof of concept. Pulm. Pharmacol. Ther. 2005; 18 (2): 83-88.

\section{Информация об авторах}

Трофименко Ирина Николаевна - к. м. н., ассистент кафедры аллергологии и пульмонологии Иркутского ГИУВ; тел.: 8-914-877-80-96, e-mail: tin11@mail.ru

Черняк Борис Анатольевич - д. м. н., проф., зав. кафедрой аллергологии и пульмонологии Иркутского ГИУВ; тел.: 8-902-568-78-70; e-mail: bores@angara.ru

Поступила 15.06.11 (с) Трофименко И. Черняк Б.А., 2011 удк 616.24-036.12-02:616.233-092 